\title{
PENGENALAN PERMAINAN TRADISIONAL INDONESIA DI KELAS BIPA
}

\author{
Prima Vidya Asteria
}

Universitas Negeri Surabaya, primaasteria@unesa.ac.id

\begin{abstract}
This study aimed to describe the introduction of Indonesian Traditional Games in Unesa BIPA's Class that includes planning, implementation, and evaluation. This study used descriptive qualitative method. This research was conducted in classes BIPA Unesa in the course Introduction to Indonesian Culture, February 17, 2016. The subjects were students who take the program BIPA Unesa Dharmasiswa class of 11 students. The stages of this study include the initial, core, end. In the early stage, researcher collecting information about situation in BIPA class at Unesa and creating syllabus and instruments. At the core stage, researcher doing learning and teaching process based on syllabus. At the last stage is evaluating of learning. Things that exist during the learning and teaching process that the students are very enthusiastic attention and focus on lecturer and model. Based on the task, students' ability is quite good with an average of 83 .
\end{abstract}

Keywords: traditional game, culture, congklak, BIPA (Bahasa Indonesia for Non native Speaker)

\section{PENDAHULUAN}

Bahasa Indonesia telah berkembang pesat sejak dikukuhkan sebagai bahasa persatuan pada 28 Oktober 1928 hingga sekarang. Dalam perkembangannya, bahasa Indonesia juga telah diajarkan untuk orang asing, baik di dalam negeri atau luar negeri. BIPA merupakan program pengajaran bahasa Indonesia yang diajarkan untuk orang asing (Asteria, 2015). Departemen Pendidikan Nasional Republik Indonesia melalui Badan Pengembangan dan Pembinaan Bahasa, telah melaksanakan upaya internasionalisasi Bahasa Indonesia dengan menyelenggarakan kegiatan pengajaran Bahasa Indonesia untuk Penutur Asing (BIPA) sejak tahun 2000 (Robita, 2012).

BIPA mempunyai peran yang amat penting dan strategis dalam memperkenalkan Indonesia kepada masyarakat internasional. Hal itu karena Pengajaran BIPA di samping merupakan media untuk menyebarluaskan bahasa Indonesia, juga merupakan media untuk menyampaikan berbagai informasi tentang Indonesia, termasuk memperkenalkan masyarakat dan budaya Indonesia. Dengan demikian, orang asing yang mempelajari 
bahasa Indonesia akan semakin memahami masyarakat dan budaya Indonesia secara lebih komprehensif. Pemahaman itu pada gilirannya dapat meningkatkan rasa saling pengertian dan saling menghargai sehingga makin meningkatkan pula persahabatan dan kerja sama antarbangsa (badanbahasa.kemdikbud.go.id, 2012).

Upaya Pemerintah Indonesia dalam mengembangkan pembelajaran BIPA tercantum dalam visi dari Badan Pengembangan dan Pembinaan Bahasa, yaitu: pengajaran BIPA bertujuan untuk menjadikan Bahasa Indonesia sebagai Bahasa Internasional antarbangsa dengan cara menunjukkan citra positif Indonesia. Langkah nyata untuk mewujudkan visi tersebut tercermin dalam misi sebagai berikut:

(1) memperkenalkan masyarakat dan budaya Indonesia di dunia internasional dalam rangka meningkatkan citra Indonesia di luar negeri,

(2) meningkatkan kerja sama yang lebih erat dan memperluas jaringan kerja dengan lembaga-lembaga penyelenggara pengajaran BIPA, baik di dalam maupun di luar negeri,

(3) memberikan dukungan dan fasilitasi terhadap lembaga-lembaga penyelenggara pengajaran BIPA, baik di dalam maupun di luar negeri,

(4) meningkatkan mutu pengajaran BIPA, baik di dalam maupun di luar negeri, dan

(5) meningkatkan mutu sumber daya penyelenggara pengajaran BIPA di dalam dan di luar negeri.

Oleh karena itu, sudah sewajarnya Badan Pengembangan dan Pembinaan Bahasa dijadikan sebagai standar acuan bagi lembaga-lembaga nasional, regional maupun lokal yang bergerak di bidang pengajaran BIPA (Ardiansyah, 2012).

Pembelajaran Bahasa Indonesia bagi penutur Asing (BIPA) bertujuan untuk mengenalkan bahasa Indonesia kepada penutur asing untuk berbagai kepentingan, baik pengajaran maupun komunikasi praktis. Salah satu materi yang diajarkan dalam pembelajaran BIPA adalah materi Pengenalan Budaya Indonesia. Melaui materi-materi Pengenalan Budaya Indonesia, mahasiswa penutur asing mendapatkan pengetahuan bahasa dan budaya yang dapat membantu mereka dalam praktik komunikasi bahasa Indonesia. 
Budaya berasal dari kata budi dan daya. Budi merupakan unsur rohani, sedangkan daya adalah unsur jasmani manusia (Herimanto, 2009). Dengan demikian, budaya dapat diartikan sebagai segala hasil budi dan daya (rohani dan jasmani) manusia yang dimiliki bersama oleh sekelompok orang dan memiliki nilai-nilai yang diwariskan dari generasi ke generasi. Setiap negara tentu memiliki budaya masing-masing yang menjadikannya khas dan berbeda dari negara lain. Ada banyak aspek budaya Indonesia yang dapat dimanfaatkan dalam pembelajaran BIPA. Pengajar BIPA dapat memilih unsur-unsur budaya mana yang diperlukan disajikan sebagai materi pembelajaran (Ruskhan, 2007).

Manusia dan kebudayaan senantiasa mengalami perubahan (Spencer dalam Ritzer, 2003:50). Salah satu perubahan tersebut adalah permainan tradisional yang dulu dijadikan permainan sehari-hari, tetapi sekarang tidak lagi sebagai permainan sehari-hari. Padahal, Kurniati (2011:13) dan Cahyono (2011:2) menyatakan bahwa permainan anak tradisional dapat membentuk karakter positif kebersamaan, kejujuran, tanggung jawab, sikap lapang dada (kalau kalah), dorongan berprestasi, mengembangkan sikap empati terhadap teman, menaati aturan, serta menghargai orang lain.

Indonesia memiliki permainan anak tradisional yang kaya akan nilai (Haerani, 2013). Permainan tradisional sangat baik untuk melatih fisik dan mental anak. Para psikolog menilai bahwa sesungguhnya mainan tradisional mampu membentuk motorik anak, baik kasar maupun halus. Salah satu permainan yang mampu membentuk motorik anak adalah congklak/dakon. Pada permainan ini pemain dituntut untuk memegang biji secara utuh sembari meletakkannya satu-satu di kotakkannya dengan satu tangan (Nahardianti, 2013). Oleh karena itu, penulis ingin mendeskripsikan Pengenalan Permainan Tradisional Indonesia di Kelas BIPA Unesa yang mencakup perencanaan, pelaksanaan, dan evaluasi pembelajaran.

Permainan tradisional dalam penelitian ini dibatasi pada permainan congklak. Sementara kelas BIPA yang digunakan adalah kelas BIPA Unesa. Penelitian ini dilakukan di kelas BIPA Unesa pada mata kuliah Pengenalan Budaya Indonesia, 17 Februari 2016. Penelitian ini menggunakan metode deskriptif kualitatif. Subjek penelitian ini adalah mahasiswa yang mengikuti program Dharmasiswa di kelas BIPA Unesa sebanyak 11 mahasiswa. Tahap-tahap penelitian ini mencakup awal, inti, akhir. Pada tahap awal dilakukan penggalian informasi tentang situasi dan kondisi kelas BIPA Unesa 
dan menyusun silabus $\&$ instrumen. Pada tahap inti peneliti melaksanakan pembelajaran BIPA dengan topik pengenalan permainan tradisional Indonesia sesuai dengan silabus yang telah disusun dan mengevaluasi pembelajaran. Pada tahap akhir dilakukan evaluasi pembelajaran.

Data berupa hasil pengamatan selama proses pembelajaran dan tes tulis. Teknik pengumpulan data dengan observasi dan tes tulis. Dalam observasi peneliti mengamati dan berperan serta. Teknik tes berupa tes tulis tentang pemahaman terhadap permainan congklak yang telah dipelajari dan dipraktikkan bersama. Teknik analisis data yaitu dengan pemberian skor dan nilai terhadap hasil tes tulis yang dilakukan. Selanjutnya dilakukan triangulasi sumber (membandingkan data hasil observasi dengan data hasil wawancara dan data dokumen.

\section{PEMBAHASAN}

1. Perencanaan Pengenalan Permainan Tradisional Indonesia dalam Pembelajaran BIPA

Pada tahap awal dilakukan penggalian informasi tentang situasi dan kondisi kelas BIPA Unesa, menyusun silabus dan instrumen, dan menyiapkan kebutuhan permainan congklak. Pertama, peneliti yang sekaligus pengajar BIPA di Unesa telah mengetahui situasi dan kondisi kelas BIPA Unesa. berikut adalah data tentang mahasiswa BIPA Unesa.

\begin{tabular}{|l|l|l|l|}
\hline No & Kode & Nama & Asal \\
\hline 1 & M1 & Theresa Moia & Papua Nugini \\
\hline 2 & M2 & Suraj & Uzbekistan \\
\hline 3 & M3 & Siti Aisyah Maming & Thailand \\
\hline 4 & M4 & Suttichai Phraiphruek & Thailand \\
\hline 5 & M5 & Qian Yancheng & China \\
\hline 6 & M6 & Yuan Li Wen & China \\
\hline 7 & M7 & Chen Miyang & China \\
\hline
\end{tabular}




\begin{tabular}{|l|l|l|l|}
\hline 8 & M8 & Yuan Zhe & China \\
\hline 9 & M9 & Sun Xuemin & China \\
\hline 10 & M10 & Xie Xiaoyi & China \\
\hline 11 & M11 & Claudiah & Madagaskar \\
\hline
\end{tabular}

Dari 11 mahasiswa BIPA Unesa, enam mahasiswa China (m5, m6, m7, m8, m9, m10) telah memiliki kemampuan bahasa Indonesia yang paling tinggi dibandingkan mahasiswa lainnya. Hal ini disebabkan mereka telah mendapatkan mata kuliah bahasa Indonesia di PT asal. Selain itu, mereka memiliki hubungan yang sangat dekat antara satu dengan yang lain. Sementara itu, kedua mahasiswa asal Thailand (m3, m4) memiliki kemampuan bahasa Indonesia sedang. Pada awalnya mereka belum bisa bahasa Indonesia, tetapi karena mereka juga menggunakan bahasa Melayu, maka mereka lebih mudah memahami bahasa Indonesia. Ketiga mahasiswa lain (M1, M2, M11) memiliki kemampuan bahasa Indonesia yang kurang.

Kedua, hal yang dilakukan dosen adalah menyusun silabus dan instrumen. Silabus sederhana dengan tema Permainan Tradisional disajikan seperti bagan silabus berikut.

Silabus Mengenal Permainan Tradisional Indonesia

\begin{tabular}{|c|c|c|c|c|c|c|c|}
\hline \multirow{2}{*}{$\begin{array}{l}\text { Durasi } \\
\text { Waktu }\end{array}$} & \multirow[t]{2}{*}{ Subtema } & \multicolumn{4}{|c|}{ Keterampilan } & \multirow[t]{2}{*}{ Fokus Bahasa } & \multirow{2}{*}{$\begin{array}{l}\text { Informasi } \\
\text { Tambahan }\end{array}$} \\
\hline & & Menyimak & Membaca & Menulis & Berbicara & & \\
\hline $2 \times 50^{\prime}$ & $\begin{array}{l}\text { CONGKLAK } \\
\text { - } \text { Menjelaskan } \\
\text { konsep } \\
\text { permainan } \\
\text { tradisional } \\
\text { congklak. } \\
\text { - Mengidentifi } \\
\text { kasi langkah- }\end{array}$ & $\begin{array}{l}\text { Mengidentifi } \\
\text { kasi } \\
\text { langkah- } \\
\text { langkah } \\
\text { bermain } \\
\text { congklak }\end{array}$ & $\begin{array}{l}\text { Menandai } \\
\text { kata-kata } \\
\text { kunci yang } \\
\text { ada dalam } \\
\text { materi }\end{array}$ & $\begin{array}{l}\text { Menulis } \\
\text { kesan } \\
\text { setelah } \\
\text { bermain } \\
\text { congklak } \\
\text { Menulis } \\
\text { langkah- }\end{array}$ & $\begin{array}{l}\text { Diskusi } \\
\text { tentang } \\
\text { permainan } \\
\text { tradisional } \\
\text { congklak }\end{array}$ & $\begin{array}{ll}\text { - } & \text { Kalimat seru } \\
\text { Ayo, } \\
\text { sekarang } \\
\text { giliranmu! } \\
\text { - } \text { Deret hitung } \\
\text { Satu, dua, } \\
\text { tiga, empat, } \\
\text { dst. (saat }\end{array}$ & $\begin{array}{l}\text { Dengan } \\
\text { bermain } \\
\text { congklak, } \\
\text { kita dapat } \\
\text { berlatih } \\
\text { menyusun } \\
\text { strategi } \\
\text { dalam }\end{array}$ \\
\hline
\end{tabular}




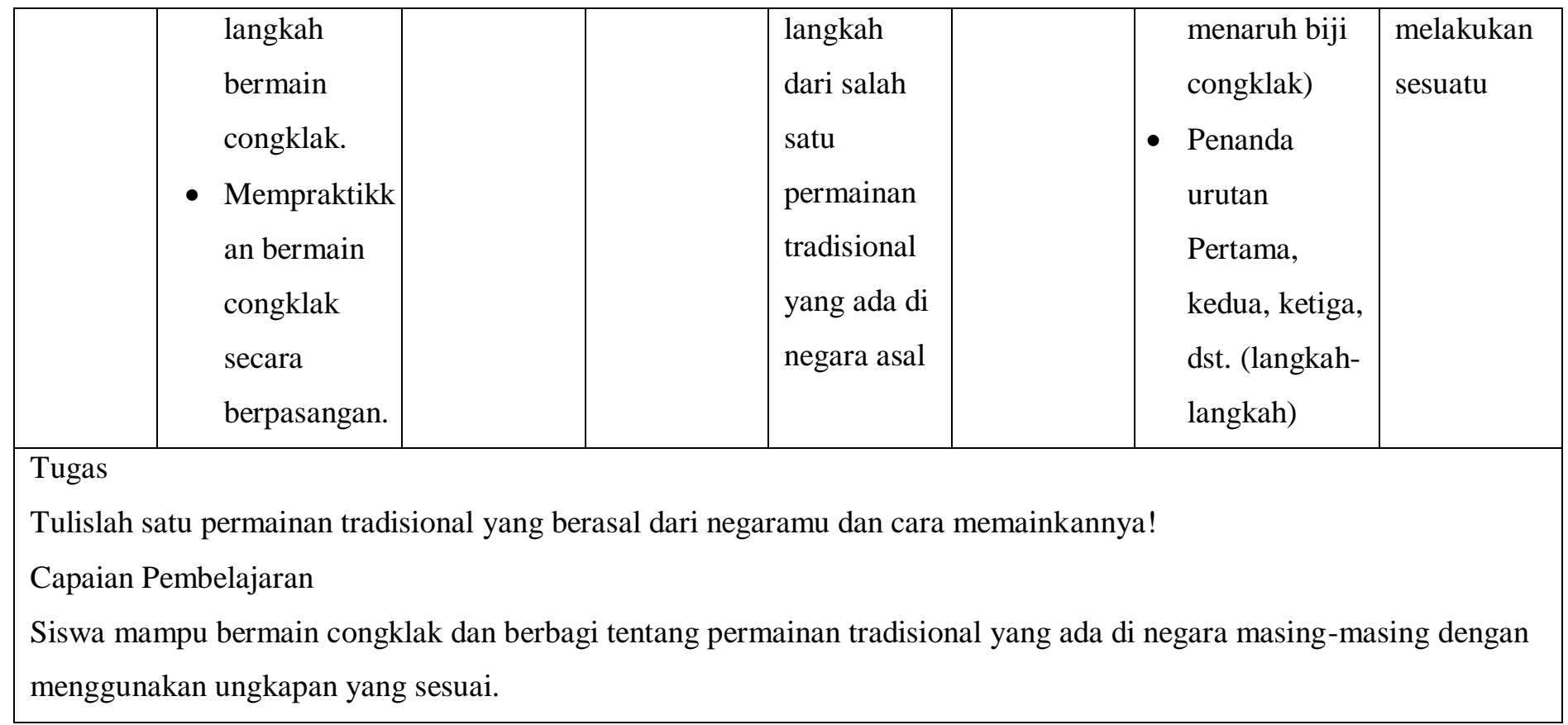

Selain silabus pembelajaran, peneliti juga menyusun instrumen yaitu pedoman observasi berupa isian data tentang kegiatan dan tanggapan mahasiswa selama pembelajaran. Sementara soal tes tulis terkait materi mengenal permainan tradisional Indonesia adalah sebagai berikut.

\section{Kerjakan Soal Berikut!}
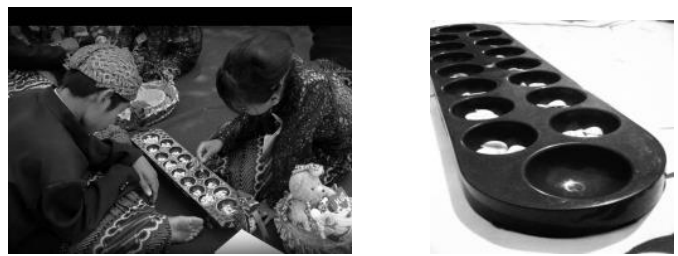

Permainan di atas adalah permainan(1) Indonesia bernama(2). Jumlah pemainnya ada(3).......orang. Nilai-nilai yang dapat dipelajari dari permainan tersebut adalah (4) (.............................................................n (5) Salah satu permainan yang berasal dari negaramu adalah (6).............. Cara memainkan permainan ini yaitu 
(7)

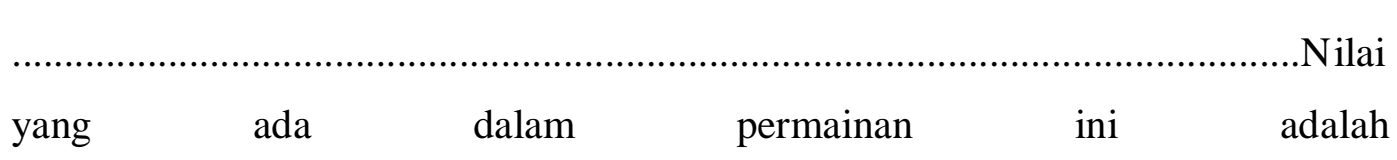

(8)

2. Pelaksanaan Pengenalan Permainan Tradisional Indonesia dalam Pembelajaran BIPA

Pada tahap pelaksanaan pembelajaran, dosen melaksanakan pembelajaran BIPA dengan topik pengenalan permainan tradisional Indonesia sesuai dengan silabus yang telah disusun. Berdasarkan silabus tersebut, langkah-langkah pembelajaran secara umum yaitu:

(1) Dosen menyampaikan tujuan pembelajaran yaitu mengenal permainan tradisional Indonesia (congklak)

(2) Dosen menyampaikan hal-hal yang akan dilakukan dalam pembelajaran

(3) Mahasiswa memperhatikan dua model yang mempraktikkan permainan congklak (sembari mengidentifikasi langkah-langkah bermain congklak).

(4) Mahasiswa menandai kata-kata kunci / kata-kata sulit yang ada dalam materi

(5) Mahasiswa menyimak penjelasan dosen tentang kosa kata terkait congklak dan konsep permainan tradisional congklak, serta nilai-nilai yang ada dalam permainan congklak

(6) Mahasiswa dan dosen bertanya jawab tentang kesulitan yang dialami mahasiswa dalam memahami permainan congklak

(7) Mahasiswa berbagi (secara lisan) tentang salah satu permainan tradisional dari negara masing-masing

(8) Dosen memberikan penguatan tentang fokus kebahasaan (kalimat seru, deret hitung, penanda urutan) 
(9) Mahasiswa ke luar kelas dan bermain congklak secara berpasangan

(10) Dosen mendampingi masisng-masing pasangan secara bergiliran dan menanyakan kesan mahasiswa tentang permainan congklak

(11) Dosen menutup perkuliahan dan memberi lembar tugas untuk dikumpulkan keesokan harinya.

Hal-hal yang ada pada catatan selama pelaksanaan pembelajaran sebagian besar mahasiswa sangat antusias memperhatikan model yang mempraktikkan bermain congklak. Seperti pada gambar berikut.

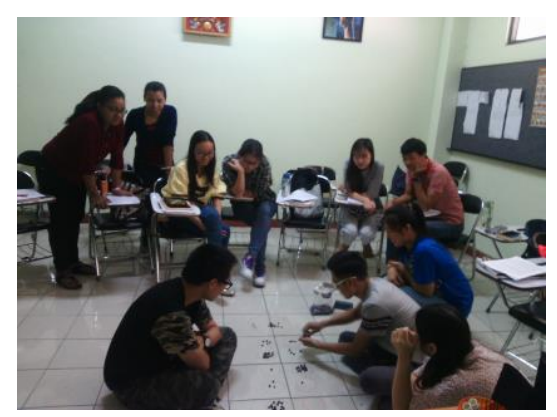

Gambar 1. Mahasiswa model bermain congklak

Semua siswa fokus pada saat dosen menjelaskan nilai-nilai yang terdapat dalam permainan congklak. Nilai-nilai ini penting disampaikan karena permainan tradisional memiliki unsur budaya yang melekat kuat dan harus terus dilestarikan (Yudiwinata dan Handoyo, 2014).

Berikut adalah nilai-nilai dalam permainan congklak yang disampaikan oleh dosen kepada mahasiswa.

(1) Permainan Congklak memiliki 7 lubang dan masing-masing berisi 7 biji. Tujuh adalah jumlah hari dalam satu minggu. Jumlah biji yang ada pada lubang kecilpun sama. Artinya, tiap orang mempunyai jatah waktu yang sama dalam seminggu, yaitu 7 hari. 
(2) Ketika biji diambil dari satu lubang, ia mengisi lubang yang lain, termasuk lubang induknya. Pelajaran dari fase ini adalah, tiap hari yang kita jalani, akan mempengaruhi hari-hari kita selanjutnya, dan juga hari-hari orang lain. Apa yang kita lakukan hari ini menentukan apa yang akan terjadi pada masa depan kita. Apa yang kita lakukan hari ini bisa jadi sangat bermakna pula bagi orang lain.

(3) Biji diambil, kemudian diambil lagi, juga berarti bahwa hidup itu harus memberi dan menerima. Tidak bisa mengambil terus, kalau tidak memberi.

(4) Biji diambil satu persatu, tidak boleh semua sekaligus. Maksudnya, kita harus jujur untuk mengisi lubang kita. Kita harus jujur mengisi hidup kita. Satu persatu, sedikit demi sedikit, asalkan jujur dan baik, lebih baik daripada banyak namun tidak jujur. Satu persatu biji yang diisi juga bermakna bahwa kita harus menabung tiap hari untuk hari-hari berikutnya. Kita juga harus mempunyai "simpanan/tabungan", yaitu biji yang berada di lubang induk.

(5) Strategi diperlukan dalam permainan ini agar biji kita tidak habis diambil lawan. Hikmahnya adalah, hidup ini adalah persaingan, namun bukan berarti kita harus bermusuhan. Karena tiap orang juga punya kepentingan dan tujuan yang (mungkin) sama dengan tujuan kita, maka kita harus cerdik dan strategis.

(6) Pemenang adalah yang jumlah bijinya di lubang induk paling banyak, maksudnya adalah mereka yang menjadi pemenang/ mereka yang sukses adalah mereka yang paling banyak amal kebaikannya. Mereka yang banyak tabungan kebaikannya, mereka yang menabung lebih banyak, dan mereka yang tahu strategi untuk mengumpulkan rezeki.

Setelah dosen menyampaikan nilai-nilai tersebut, mahasiswa secara bergantian juga menceritakan tentang permainan tradisional yang ada di negara 
mereka dan disimak oleh teman-teman lain. Mahasiswa dari China (M5) menyatakan bahwa ada permainan tradisional China yang agak sama dengan congklak, tetapi tidak menggunakan biji atau batu.

Selain itu, kendala lain yang muncul pada saat pembelajaran adalah saat pembentukan kelompok. Salah satu mahasiswa dari China (M7) tidak mau dipasangkan dengan teman sekelompoknya. Ia meminta agar berpasangan dengan teman yang juga berasal dari China yang berasal dari sesama negara. Pada saat menghadapi kendala ini, dosen memberikan pengertian bahwa kegiatan ini adalah salah satu proses pembelajaran berbasil multikultural sehingga perbedaan negara tidak harus dihindari. Dosen memberikan pemahaman justru apabila dalam satu kelompok berasal dari negara yang berbeda justru bermanfaat karena anggota kelompok dapat belajar dan berinteraksi satu sama lain serta memberi kesempatan mereka berbagi terkaitan kebudayaan negara asal termasuk permainan tradisional. Pada akhirnya, mahasiswa tersebut menerima dan melanjutkan kegiatan pembelajaran berupa praktik bermain congklak.

Pada saat praktik bermain congklak secara berpasangan, mahasiswa BIPA bermain congklak di lorong gedung T4 Jurusan Bahasa dan Sastra Indonesia Universitas Negeri Surabaya. Proses bermain tampak pada gambar berikut.

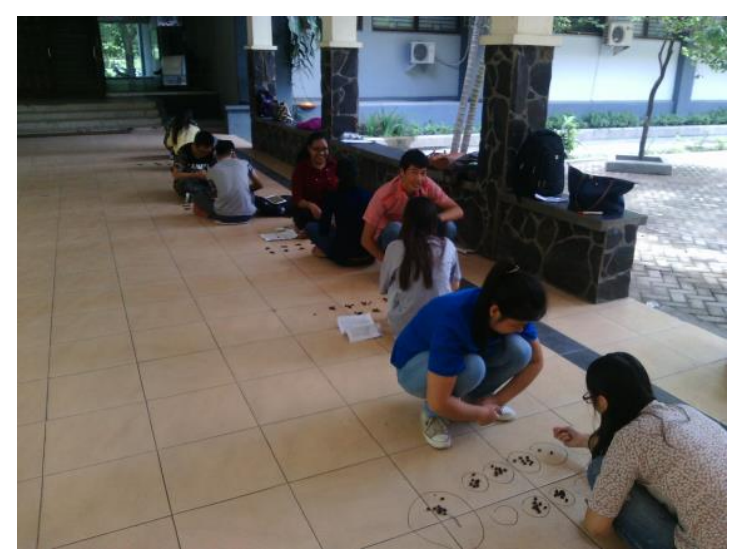

Gambar 2. Mahasiswa BIPA secara berpasangan bermain congklak 
Pemilihan tempat di lorong ini dimaksudkan agar mahasiswa reguler dapat menyaksikan dan menjadi daya tarik. Hal ini terbukti dari beberapa mahasiswa reguler yang mendekati dan melihat ketika mahasiswa BIPA bermain congklak. selain itu ada pula beberapa mahasiswa reguler yang mengambil foto. Hal ini salah satu bentuk rasa senang karena mahasiswa asing yang ada di Unesa bersedia belajar bermainan permainan tradisional Indonesia yang mugkin tidak ada di negara asal mereka.

3. Evaluasi Pengenalan Permainan Tradisional Indonesia dalam Pembelajaran BIPA

Pada tahap evaluasi, dosen mengevaluasi hasil observasi dan hasil tes tulis mahasiswa. Materi pengenalan permainan tradisional Indonesia sangat menarik bagi mahasiswa BIPA. Permainan tradisional di Indonesia sangatlah beragam dan berkembang berdasarkan kebutuhan masyarakat setempat (Arista, 2012). Dengan demikian, peneliti dapat memilih permainan tradisional Indonesia yang akan diajarkan. Secara umum, seluruh mahasiswa sudah menunjukkan perilaku positif selama pembelajaran (konsentrasi, bertanya, menjawab, dan melakukan instruksi yang diberikan dosen). Hanya ada kendala kecil yaitu ada mahasiswa yang terlambat, ke kamar kecil, dan membalas sms.

Berdasarkan ter tulis dari tugas yang diberikan oleh dosen, kemampuan mahasiswa BIPA mengenal permainan tradisional Indonesia tergolong baik dengan rata-rata 83. Rincian nilai tiap mahasiswa sebagai berikut.

\begin{tabular}{|l|l|l|}
\hline No & Kode & Nilai \\
\hline 1 & M1 & 62,5 \\
\hline 2 & M2 & 75 \\
\hline 3 & M3 & 75 \\
\hline 4 & M4 & 87,5 \\
\hline
\end{tabular}

156 | http://journal.unesa.ac.id/index.php/paramasastra 


\begin{tabular}{|l|l|l|}
\hline 5 & M5 & 87,5 \\
\hline 6 & M6 & 87,5 \\
\hline 7 & M7 & 100 \\
\hline 8 & M8 & 100 \\
\hline 9 & M9 & 87,5 \\
\hline 10 & M10 & 87,5 \\
\hline 11 & M11 & 62,5 \\
\hline
\end{tabular}

Lebih lanjut, permainan tradisional dapat memberikan dampak yang sangat baik dalam membantu mengembangkan keterampilan emosi. Selain itu, permainan tradisional juga dapat melatih kemampuan sosial para pemainnya karena pada umumnya permainan tradisional membutuhkan lebih dari satu pemain (Syafii, 2013). Inilah yang membedakan permainan tradisional dengan permainan modern. Oleh karena itu, permainan tradisional dapat dijadikan alternatif materi dalam pembelajaran pengenalan budaya Indonesia.

\section{SIMPULAN}

Pembelajaran BIPA merupakan pembelajaran yang kompleks karena beragam budaya bertemu dalam satu kelas. Salah satu materi yang dapat dimasukkan dalam pembelajaran pengenalan budaya di kelas BIPA adalah materi Pengenalan Permainan Tradisional Indonesia, salah satunya congklak. Tahap-tahap penelitian ini mencakup awal, inti, akhir. Pada tahap awal dilakukan penggalian informasi tentang situasi dan kondisi kelas BIPA Unesa dan menyusun silabus \& instrumen. Pada tahap inti peneliti melaksanakan pembelajaran BIPA dengan topik pengenalan permainan tradisional Indonesia sesuai dengan silabus yang telah disusun dan mengevaluasi pembelajaran. Pada tahap akhir dilakukan evaluasi pembelajaran. Hal-hal yang ada pada catatan selama pelaksanaan pembelajaran sebagian besar mahasiswa sangat antusias memperhatikan model yang mempraktikkan bermain congklak. Semua siswa fokus pada saat dosen menjelaskan nilai-nilai yang terdapat dalam permainan congklak. Berdasarkan ter tulis 
dari tugas yang diberikan oleh dosen, kemampuan mahasiswa BIPA mengenal permainan tradisional Indonesia tergolong baik dengan rata-rata 83.

\section{DAFTAR PUSTAKA}

Adryansyah. 2012. Profil Bipa Badan Pengembangan dan Pembinaan Bahasa. (Online) (http://badanbahasa.kemdikbud.go.id/lamanbahasa/info_bipa) . Diakses 2 Februari 2016).

Arista, Eka Candra. 2012. Pengaruh Permainan Tradisional Terhadap Keterampilan Anak Prasekolah. Skripsi. Fakultas Dakwah IAIN Sunan Ampel Surabaya, 2012.

Asteria, Prima Vidya. 2015. BIPA for Business: Peluang Pengajaran BIPA di era MEA. Prosiding Konferensi Internasional Pengajaran BIPA IX di Bali Oktober 2015.

Cahyono, N. 2011. Transformasi Permainan Anak Indonesia. Artikel. http://-permata nusantara.blogspot.com. Diakses pada tanggal 25 April 2016.

Herimanto, Winarno. 2009. Ilmu Sosial Dasar dan Budaya Dasar. Jakarta Timur: Bumi Aksara Jakarta Timur.

Kurniati, E. 2011. Program Bimbingan untuk Mengembangkan Keterampilan Sosial Anak Melalui Permainan Tradisional. Surakarta: Skripsi Universitas Muhammadiyah Surakarta. Tidak diterbitkan.

Moleong, Lexy J. 2009. Metodologi Penelitian Kualitatif. Bandung: Rosda Karya.

Nahardianti. 2013. Permainan Tradisional Indonesia. (Online) (http://iqnahardianti91.blogspot. com/2013/01 permainan-tradisionalIndonesia.html,diakses 16 April 2016).

Nur, Haerani. Membangun Karakter Anak melalui Permainan Anak Tradisional. Jurnal Pendidikan Karakter, Tahun III, Nomor 1, Februari 2013. 87-94

Ritzer, George \& Douglas J. Goodman. 2009. Teori Sosiologi : Dari Teori Sosiologi Klasik sampai Perkembangan Mutakhir Teori Sosial Postmodern. Yogyakarta : Kreasi Wacana.

Robita. 2012. Sejarah dan Perkembangan BIPA. (Online) (https://robita.wordpress.com/2012/06/20/sejarah-dan-perkembangan-bipa/).

Diakses 1 Feruari 2016.

158 | http://journal.unesa.ac.id/index.php/paramasastra 
Prima Vidya Asteria, Pengenalan Permainan Tradisional...(hlm. 146 - 159)

Ruskhan, Abdul Gaffar. Pemanfaatan Keberagaman Budaya Indonesia Dalam Pengajaran Bahasa Indonesia Bagi Penutur Asing (BIPA). Makalah yang disajikan dalam Seminar Pengajaran Bahasa Indonesia Pertemuan Asosiasi Jepang-Indonesia di Nanzan Gakuen Training Center, Nagoya, Jepang, 10-11 November 2007

Syafii, Nur. 2013. Lunturnya Budaya Permainan Tradisional Bagi Anak-Anak Pada Era Modern Di Desa Sekaran Lamongan. Skripsi UIN Sunan Ampel Surabaya Tidak diterbitkan.

Yudiwinata, Hikmah Prisia dan Pambudi Handoyo. Paradigma. Volume 02 Nomer 03 Tahun 2014. 